Brit. J. industr. Med., 1965, 22, 317.

\title{
VALUE OF ED s0 TESTING IN ASSESSING HAZARDS OF ACUTE POISONING BY CARBAMATES AND ORGANOPHOSPHATES
}

\author{
BY \\ M. VANDEKAR, E. REINER, B. SVETLIČIĆ,** and T. FAJDETIĆ \\ From the Institute for Medical Research, Yugoslav Academy of Sciences and Arts, \\ Zagreb, Yugoslavia \\ (RECEIVED FOR PUBLICATION MAY 21, 1965)
}

\begin{abstract}
It is shown from the kinetics of inhibition of cholinesterase by $N$-methylcarbamates and organophosphates that the $\mathbf{L D}_{50}$ dose is likely to be a much greater multiple of the dose causing signs of poisoning in $50 \%$ of the animals (the $\mathrm{ED}_{50}$ ) for the carbamates than for the organophosphates. The expected difference was demonstrated by a comparison of the $\mathrm{LD}_{50} \mathrm{~s}$ and $\mathrm{ED}_{50} \mathrm{~s}$, intravenous and intramuscular, of five carbamates (2-isopropoxyphenyl $N$-methylcarbamate, 3-isopropylphenyl $N$-methylcarbamate, 6-chloro-3,4-xylyl $N$-methylcarbamate, 3,4,5-trimethylphenyl $N$-methylcarbamate, and 3-methyl-5-isopropylphenyl $N$-methylcarbamate) and two organophosphorus compounds (diethyl 4-nitrophenyl phosphate and dimethyl 4-nitrophenyl phosphate). The slightest evoked tremor was chosen as the most reliable sign of poisoning from which to estimate the $\mathrm{ED}_{50}$ values. Carbamates gave much greater $\mathrm{LD}_{50} / \mathrm{ED}_{50}$ ratios than organophosphorus compounds. It is likely that occupational exposure to carbamates will produce incapacitating symptoms at doses well below lethal levels.
\end{abstract}

Two groups of insecticides with anticholinesterase action are in widespread use-organophosphorus compounds and $N$-methylcarbamate esters. There are good theoretical reasons for expecting that the carbamates will produce the first distinct signs of poisoning at very much smaller fractions of their $\mathrm{LD}_{50}$ values than will the organophosphorus compounds.

Thus organophosphorus compounds can be regarded as irreversible inhibitors, so that inhibition of cholinesterase is progressive, as described by Aldridge and Davison (1952). For such inhibitors the activities of the uninhibited and partially inhibited enzymes are related by the equation:

$$
\ln v_{o} / v_{i}=k_{i} c_{i} t
$$

where $v_{o}$ and $v_{i}$ are the activities before and after inhibition, $c_{i}$ is the concentration of inhibitor acting for time $t$, and $k_{i}$ is the rate constant for the reaction between inhibitor and enzyme.

In the case of carbamates, interaction with the enzyme involves both inhibition and re-activation

*Present address: 'A. Stampar' School of Public Health, Medical Faculty, University of Zagreb, Zagreb, Yugoslavia.
(Wilson, Hatch, and Ginsburg, 1960), so that after a certain time an equilibrium is reached, i.e., the rates of inhibition and re-activation are equal. The equilibrium is described by the equation (Reiner, unpublished):

$$
K=v_{i} c_{i} /\left(v_{o}-v_{i}\right)
$$

where $K$ stands for the equilibrium constant. This equation is equally applicable whether equilibrium is reached through carbamylation of the enzyme or by the formation of a reversible complex between enzyme and inhibitor.

In the Figure the inhibition of cholinesterase by carbamates and organophosphorus compounds is presented at various concentrations of inhibitor. The degree of inhibition was calculated from equation 1 for organophosphorus compounds and from equation 2 for carbamates.

In Figure a the curves were constructed for the case where both a carbamate and an organophosphate produced $12.5 \%$ inhibition at unit concentration, i.e., $c_{i}=1$. On increasing the concentration of the inhibitor the activity falls off more rapidly in the organophosphorus compounds. This difference is very pronounced at high multiples of the inhibitor 


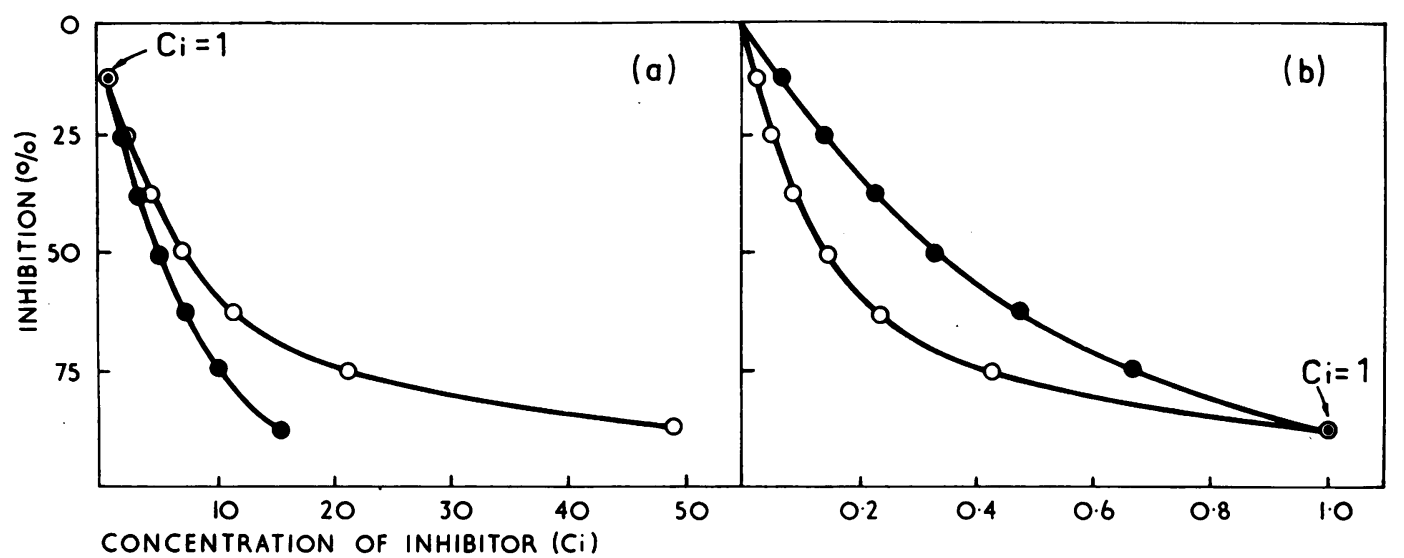

FIGURE.-Relations between theoretical percentages of inhibition of cholinesterase and concentrations of inhibitors for carbamates ( $O$ ) and organophosphates ( () . In $(a)$ unit concentration is that producing $12.5 \%$ inhibition; in $(b)$ that producing $87 \cdot 5 \%$ inhibition.

concentration, whereas for a two- to three-fold increase of the inhibitor concentration the difference in the degree of inhibition is much smaller. To produce, for instance, $87.5 \%$ inhibition, the concentration of the organophosphorus compound has to be increased 15.6 times and that of the carbamate as much as 49 times. For a $99 \%$ inhibition, the ratio of the multiples amounts to $34 \cdot 5: 636$. On the other hand, $50 \%$ inhibition is produced by similar increases in organophosphate and carbamate concentrations, the multiples being 5 and $7 \cdot 5$ respectively.

In Figure $b$ the concentration producing $87.5 \%$ inhibition was set as 1 . In this case at any concentration of inhibitor below 1 the cholinesterase activity is lower in carbamate inhibition. For instance, onetenth of the concentration of the organophosphorus compound produces $21 \%$ inhibition, whereas in the carbamate the same fraction produces $43 \%$ inhibition.

The above discussion applies strictly only in vitro. In vivo the inhibitors are likely to be metabolized, and inhibition is a complex function of dose, metabolism, and distribution. Presumably, however, the degree of inhibition required to produce signs of poisoning is the same whatever the inhibitor, and likewise the degree of inhibition to cause death. Therefore, unless metabolism and distribution vary greatly with the dose, the main conclusion should still be correct. A very much higher multiple of the dose that causes signs of poisoning should be required to produce the additional inhibition needed to cause death from carbamates than from organophosphates.

This is shown to be true from a study of the effects of five carbamates and two organophosphates in rats. The doses causing the first signs of poisoning in $50 \%$ of the rats are referred to as $\mathrm{ED}_{50}$ (effective dose) values.

\section{Materials and Methods}

Five carbamates $\uparrow$ (2-isopropoxyphenyl $N$-methylcarbamate (OMS-33), 3-isopropylphenyl $N$-methylcarbamate (OMS-162), 6-chloro-3,4-xylyl $N$-methylcarbamate (OMS-174), 3,4,5-trimethylphenyl $N$ methylcarbamate (OMS-597), and 3-methyl-5-isopropylphenyl $N$-methylcarbamate (OMS-716)) and two organophosphatesł (diethyl 4-nitrophenyl phosphate, paraoxon, and dimethyl 4-nitrophenyl phosphate, paraoxon-methyl) were used, and their $\mathbf{E D}_{50}$ and $\mathbf{L D}_{50}$ values were determined after a single intravenous or intramuscular injection into male albino rats (200-300 g.). For injections, solutions in either propylene glycol or glycerol formal were prepared. The amount of solvent injected intravenously never exceeded $1.5 \mathrm{ml} . / \mathrm{kg}$.

The $24 \mathrm{hr}$. mortality rate was used for calculating $\mathrm{LD}_{50}$ values. For calculating $\mathrm{ED}_{50}$ values the dose producing the slightest noticeable evoked tremor was chosen as an 'effective dose'. Tremor was evoked by lifting the rat 5 to $10 \mathrm{~cm}$. above a plane surface and dropping it at $5 \mathrm{~min}$. intervals to discover the peak effect. The response was compared each time with that of a control dropped simultaneously from the other hand. The control was changed after each 10 comparisons. Four rats were injected at each dose level, the levels being related by a common factor 1.26 or, less frequently, by $1 \cdot 12$. Both $L^{2} D_{50}$ and $\mathrm{ED}_{50}$ values with $95 \%$ confidence limits were deter-

†Kindly supplied through Vector Control Unit, Division of Environmental Health, World Health Organisation, Geneva.

tKindly made available by Dr. G. Schrader, Farbenfabriken Bayer, A.G., Leverkusen, Germany. 
mined by the method of moving averages (Thompson, 1947), using, where applicable, the tables given by Weil (1952).

A few preliminary experiments were carried out on dogs in which we took no measures to evoke tremors.

\section{Results}

Intravenous $L D_{50}$ and $E_{50}$ values for five carbamates and two organophosphorus compounds are given in Table 1; in the last column (A/B) the ratio between the two values is shown. In Table 2 $\mathbf{L D}_{50}$ and $\mathbf{E D}_{50}$ values obtained after intramuscular injection of the same compounds are presented; the

TABLE 1

LD $_{50}$ AND ED ED $_{s 0}$ VALUES AFTER INTRAVENOUS INJECTION OF FIVE $N$-METHYLCARBAMATES AND TWO ORGANOPHOSPHORUS COMPOUNDS

\begin{tabular}{|c|c|c|c|}
\hline Compound & $\begin{array}{l}\mathrm{LD}_{50} \text { (A) } \\
\text { (mg./kg.) }\end{array}$ & $\begin{array}{l}\mathrm{ED}_{\text {so }}(\mathrm{B}) \\
\text { (mg./kg.) }\end{array}$ & $\begin{array}{l}\text { Ratio } \\
\text { (A/B) }\end{array}$ \\
\hline OMS-33 & $\begin{array}{c}10 \cdot 6 \\
(8 \cdot 88-12 \cdot 7)\end{array}$ & $\begin{array}{c}0.334 \\
(0 \cdot 280-0 \cdot 398)\end{array}$ & $31 \cdot 8$ \\
\hline OMS-162 & $\begin{array}{c}3 \cdot 15 \\
(2 \cdot 16-3 \cdot 60)\end{array}$ & $\begin{array}{c}0 \cdot 168 \\
(0 \cdot 143-0 \cdot 198)\end{array}$ & $18 \cdot 8$ \\
\hline OMS-174 & $\begin{array}{c}3 \cdot 00 \\
(2 \cdot 51-3 \cdot 58)\end{array}$ & $\begin{array}{c}0 \cdot 144 \\
(0 \cdot 121-0 \cdot 172)\end{array}$ & $24 \cdot 2$ \\
\hline OMS-716 & $\begin{array}{c}5 \cdot 30 \\
(4 \cdot 44-6 \cdot 32)\end{array}$ & $\begin{array}{c}0 \cdot 189 \\
(0 \cdot 158-0 \cdot 225)\end{array}$ & $28 \cdot 0$ \\
\hline OMS-597 & $\begin{array}{c}31 \cdot 8 \\
(27 \cdot 8-36 \cdot 3)\end{array}$ & $\begin{array}{c}1 \cdot 50 \\
(1 \cdot 27-1 \cdot 77)\end{array}$ & $21 \cdot 6$ \\
\hline Paraoxon-methyl & $\begin{array}{c}0.457 \\
(0.419-0.498)\end{array}$ & $\begin{array}{c}0.084 \\
(0.070-0 \cdot 104)\end{array}$ & $5 \cdot 4$ \\
\hline Paraoxon & $\begin{array}{c}0.253 \\
(0 \cdot 221-0 \cdot 289)\end{array}$ & $\begin{array}{c}0.086 \\
(0.076-0.096)\end{array}$ & $2 \cdot 9$ \\
\hline
\end{tabular}

$95 \%$ confidence limits are given in brackets.

TABLE 2

LD $_{50}$ AND ED ED $_{50}$ VALUES AFTER INTRAMUSCULAR INJECTION OF $^{50}$ FIVE $N$-METHYLCARBAMATES AND TWO ORGANOPHOSPHORUS COMPOUNDS

\begin{tabular}{|c|c|c|c|}
\hline Compound & $\begin{array}{l}\mathrm{LD}_{\mathrm{s0}} \text { (A) } \\
\text { (mg./kg.) }\end{array}$ & $\begin{array}{l}\mathrm{ED}_{\mathrm{s0}}(\mathrm{B}) \\
\text { (mg./kg.) }\end{array}$ & $\begin{array}{l}\text { Ratio } \\
\text { (A/B) }\end{array}$ \\
\hline OMS-33 & $\begin{array}{c}53 \cdot 0 \\
(47 \cdot 2-59 \cdot 5)\end{array}$ & $\begin{array}{c}1 \cdot 66 \\
(1 \cdot 46-1 \cdot 90)\end{array}$ & $32 \cdot 0$ \\
\hline OMS-162 & $\begin{array}{c}13 \cdot 6 \\
(10 \cdot 7-17 \cdot 7)\end{array}$ & $\begin{array}{c}0.566 \\
(0.475-0.672)\end{array}$ & $24 \cdot 0$ \\
\hline OMS-174 & $\begin{array}{c}24 \cdot 5 \\
(23 \cdot 1-25 \cdot 9)\end{array}$ & $\begin{array}{c}0 \cdot 840 \\
(0 \cdot 704-1 \cdot 00)\end{array}$ & $29 \cdot 2$ \\
\hline OMS-716 & $\begin{array}{c}44 \cdot 1 \\
(34 \cdot 7-56 \cdot 1)\end{array}$ & $\begin{array}{c}1 \cdot 42 \\
(1 \cdot 20-1 \cdot 67)\end{array}$ & $31 \cdot 1$ \\
\hline OMS-597 & $\begin{array}{c}283 \\
(237-338)\end{array}$ & $\begin{array}{c}7 \cdot 07 \\
(5 \cdot 99-8 \cdot 33)\end{array}$ & $40 \cdot 1$ \\
\hline Paraoxon-methyl & $\begin{array}{c}1.69 \\
(1 \cdot 41-2 \cdot 01)\end{array}$ & $\begin{array}{c}0.402 \\
(0.337-0.479)\end{array}$ & $4 \cdot 2$ \\
\hline Paraoxon & $\begin{array}{c}0.446 \\
(0.379-0.525)\end{array}$ & $\begin{array}{c}0 \cdot 177 \\
(0 \cdot 150-0 \cdot 208)\end{array}$ & $2 \cdot 5$ \\
\hline
\end{tabular}

$95 \%$ confidence limits are given in brackets. ratios between the $\mathrm{LD}_{50}$ and $E D_{50}$ values are shown in the last column.

A large ratio between $\mathrm{LD}_{50}$ and $\mathrm{ED}_{50}$ values was found after both intravenous and intraperitoneal injection for every carbamate tested: a very small fraction of the $\mathrm{LD}_{50}$ could bring about a just noticeable tremorous state in rats. On the other hand, the $\mathrm{ED}_{50}$ values of the organophosphates were relatively near to the corresponding $\mathrm{LD}_{50}$ values after both intravenous and intramuscular injection.

TABLE 3

SYMPTOMS AFTER INTRAMUSCULAR INJECTION OF OMS-162 IN DOGS

\begin{tabular}{c|l|c}
\hline $\begin{array}{c}\text { Dose } \\
\text { (mg./kg.) }\end{array}$ & \multicolumn{1}{|c}{ Symptoms Observed } & $\begin{array}{c}\text { Mortality } \\
\text { Rate }\end{array}$ \\
\hline 0.1 & No symptoms & $0 / 1$ \\
0.4 & $\begin{array}{l}\text { Moderate tremor and salivation; no } \\
\text { symptoms after 2 hours }\end{array}$ & $0 / 1$ \\
1.6 & $\begin{array}{l}\text { Pronounced tremor, fasciculations, nausea; } \\
\text { rapid recovery with no symptoms after } \\
2 \text { hours }\end{array}$ & $0 / 1$ \\
12.5 & $\begin{array}{l}\text { Very pronounced tremor and salivation, } \\
\text { dyspnoea; slow recovery with no symp- } \\
\text { toms after 6 hours } \\
\text { Very pronounced tremor, salivation, con- } \\
\text { vulsions, prostration, unconsciousness; } \\
\text { vomiting; slow recovery with slight } \\
\text { symptoms after 6 hours; one animal died } \\
\text { during the night }\end{array}$ & $0 / 1$ \\
\hline 25.0 & $\begin{array}{l}\text { Very pronounced symptoms causing death } \\
\text { within 3 to 5 hours }\end{array}$ & $1 / 2$ \\
\hline
\end{tabular}

Preliminary experiments in dogs (Table 3 ) have shown that the intramuscular $\mathbf{L D}_{50}$ value for OMS-162 is about $12.5 \mathrm{mg}$. $/ \mathrm{kg}$., whereas the corresponding $\mathrm{ED}_{50}$ value is in the range 0.1 to $0.4 \mathrm{mg} . / \mathrm{kg}$. As in rats, tremor was the first noticeable symptom after the injection of lower doses.

\section{Discussion}

When determining the median dose producing symptoms $\left(E D_{50}\right)$ it is most important to decide which symptom should be chosen to serve as a reliable criterion for evaluating an 'all or none' response. We have found that the registration of the slightest evoked tremor in rats injected with low doses of anticholinesterases gives a clear-cut answer. Increased salivation, which results in more frequent swallowing, is often present as well, but it is very difficult to describe this symptom as 'positive' or 'negative'. Even in experiments on dogs, where other symptoms such as vomiting may be expected at lower doses, tremor is observed more consistently and often before other cholinergic symptoms. For these reasons the slightest evoked tremor was taken as the symptom of choice. 
The much greater $L_{50} / E_{50}$ ratio observed with carbamates than with the two organophosphorus compounds is consistent with differences in the kinetics of action of these two classes of compounds on cholinesterase. $N$-methylcarbamylated cholinesterase reactivates very rapidly (Wilson, Harrison, and Ginsburg, 1961); and in our experiments intravenous $E_{50}$ values for carbamates had to be increased as much as 20 to 30 times to reach the corresponding $\mathbf{L D}_{50}$ values. On the other hand, paraoxon produces diethylphosphorylated cholinesterase (Aldridge, 1953), which may be regarded as 'irreversibly' inhibited; and by no more than trebling the intravenous or intramuscular $\mathrm{ED}_{50}$ value of paraoxon the corresponding $\mathrm{LD}_{50}$ values were reached. Paraoxon-methyl produces an appreciably reactivatable dimethylphosphorylated enzyme (Aldridge, 1953); and the intravenous and intramuscular $\mathrm{ED}_{50}$ values were about one-fifth of the $\mathbf{L D}_{50}$ doses.

Goldberg, Johnson, Knaak and Smyth, (1963), using a more elaborate technique for the study of behavioural effects of OMS-162 in specially trained rats, have recently reported a 25:1 ratio between the intraperitoneal $\mathrm{LD}_{50}$ and the dose causing behavioural changes in $50 \%$ of animals. The $\mathrm{LD}_{50} / \mathrm{ED}_{50}$ ratios we obtained with carbamates are in good agreement with these findings, in spite of the much simpler criterion of effect we used to esimate the $\mathrm{ED}_{50}$ values.

Both from these tests and from a limited experience of cases of carbamate poisoning (Vandekar, 1965) a practical conclusion can be drawn. In cases of occupational over-exposure to carbamates it is reasonable to assume that an early warning of poisoning by the appearance of unmistakable and incapacitating symptoms may be expected long before a lethal dose is absorbed.

Since it would be unwise to assume that all $N$-methylcarbamates or all organophosphorus compounds would behave exactly as those tested, the $\mathrm{ED}_{50}$ evaluation as described in this paper is considered as a useful additional test for comparing the toxicity of new compounds with those already in use.

The theoretical approach in this paper was suggested by Dr. W. N. Aldridge, Toxicology Unit, Medical Research Council, Carshalton, during his visit to this Institute. We should like to thank him for helpful discussions.

This investigation was supported in part by a research grant from the World Health Organisation, Geneva, and by a research grant from the Research Council of Croatia, Zagreb.

\section{REFERENCES}

Aldridge, W. N. (1953). Biochem. J., 54, 442.

Aldrid., 51, 62. (1963). J., Pharmacol. exp. Ther., 141, 244.

Thompson, W. R. (1947). Bact. Rev., 11, 115.

Vandekar, M. (1965). Bull. Wld. Hlth. Org., in press.

Weil, C. S. (1952). Biometrics, 8, 249.

Wilson, I. B., Harrison, M. A., and Ginsburg, S. (1961). J.biol. Chem., 236, 1498 .

, Hatch, M. A., and Ginsburg, S. (1960). Ibid., 235, 2312. 